Blacha, L.E. (2014). El orden social en perspectiva sociológica. Collectivus, Revista de Ciencias Sociales, 1, (1), 4-27. Julio - Diciembre. ISSN: 2382-4018

Recibido: $11 / 10 / 2013$

Aceptado versión definitiva: 14/01/2014

\title{
EI ORDEN SOCIAL EN PERSPECTIVA SOCIOLÓGICA
}

\author{
LUIS E. BLACHA ${ }^{1}$ \\ (CEAR-UNQ/CONICET) \\ Roque Sáenz Peña 352, Bernal, Buenos Aires, Argentina (B1876BXD) \\ luisblacha@gmail.com; lblacha@uvq.edu.ar
}

\section{RESUMEN}

El poder y el fundamento del orden social son preocupaciones fundacionales para la sociología. Se propone una caracterización de las relaciones de poder a través de la lectura crítica de tres abordajes sociológicos complementarios que prestan especial atención a la internalización de las normas sociales. El primero vincula la socialización con el fundamento del poder. El segundo vincula la constitución del sujeto moderno con la consolidación de las estructuras administrativas racionales del Estado. El último abordaje focaliza el aspecto práctico de las interacciones sociales, donde el poder y el capital cultural se combinan para destacar la importancia de la internalización y naturalización de las normas sociales como fundamento del orden social.

Palabras clave: Poder - Normas Sociales - Estado

\footnotetext{
${ }^{1}$ Doctor en Ciencias Sociales. Investigador Asistente del Consejo Nacional de Investigaciones Científicas y Técnicas (CONICET)- CEAR-UNQ. 
Blacha, L.E. (2014). El orden social en perspectiva sociológica. Collectivus, Revista de Ciencias Sociales, 1, (1), 4-27. Julio - Diciembre. ISSN: 2382-4018

THE SOCIAL ORDER IN A SOCIOLOGICAL PERSPECTIVE

\section{ABSTRACT}

The power and the foundation of the social order are foundational concepts for the sociological perspective. We propose a characterization of the power relationships through a critical reading of three sociological approaches focus their attention to the internalization of social rules. The first perspective links the socialization with the foundation of power. The second links the constitution of the modern subject with consolidation rational administrative structures of the state. The latter approach focuses on practical aspects of social interactions, where power and cultural capital combinates to highlight the importance of internalization and naturalization of social rules as the foundation of social order.

Keywords: Power - Social rules - State

\section{Introducción}

El poder y el fundamento del orden social suponen preocupaciones fundacionales para la sociología, que resultan un punto de contacto entre las perspectivas clásicas y contemporáneas. Tanto el positivismo de Auguste Comte como la sociología de Talcott Parsons dan cuenta de la importancia del orden en la tradición sociológica como un asunto central de la disciplina. EI positivista francés Auguste Comte, entiende que la sociología debe comprender el devenir de la historia para "contribuir a la realización del orden fundamental" (Aron, 1996, p. 91; Comte, 1988). En el caso del sociólogo norteamericano Parsons, es posible afirmar que su preocupación por explicar el orden social resulta en "una especie de modelo universal" (Wright Mills, 2005, p. 66).

Se propone en este trabajo una caracterización de las relaciones de poder a través de tres abordajes sociológicos complementarios que prestan especial atención a la internalización de las normas sociales en un contexto donde "la independencia del individuo vuelve problemático el "orden" y esta 
Blacha, L.E. (2014). El orden social en perspectiva sociológica. Collectivus, Revista de Ciencias Sociales, 1, (1), 4-27. Julio - Diciembre. ISSN: 2382-4018

problematización del orden vuelve posible la sociología" (Alexander, 2000, p. 20). El primero vincula la socialización con el fundamento del poder, al condicionar las acciones individuales con implicancias sociales. Es la perspectiva weberiana y su influencia en la elite del poder de Wright Mills que explican el orden social a través de la internalización de normas y con la mediación de estructuras administrativas.

La lectura sociológica de El malestar en la cultura de Sigmund Freud que propone la sociología figuracional de Norbert Elias constituye el segundo abordaje propuesto. A través de un estudio temporalmente amplio, se reconstruye el vínculo entre la constitución del sujeto moderno y el establecimiento de las instituciones administrativas racionales del Estado. El poder es considerado como un proceso dinámico que delinea el entramado de individuos interdependientes que constituye el contexto social o configuración.

El último abordaje aquí presentado focaliza el aspecto práctico de las interacciones sociales. Supone el establecimiento de puntos de contacto entre la sociología de la cultura de Pierre Bourdieu y la gubernamentalidad de Michel Foucault. En ambos enfoques se combinan poder y capital cultural para destacar la importancia de la internalización y naturalización de las normas sociales como fundamento del orden social.

A través de una lectura crítica, la propuesta de este estudio es establecer un diálogo entre estas tres perspectivas. Con el fin de caracterizar y ponderar la importancia del orden social como problemática fundacional de las ciencias sociales en general. $Y$ de la sociología en particular que define desde este concepto uno de sus objetos específicos de estudio.

\section{Poder y socialización}

La interpretación del poder como una relación social que formula la sociología comprensiva de Max Weber (1864- 1920) es un momento fundacional en los estudios de la disciplinares de la temática. Scribano (2009) destaca el carácter "potencial" de estas interacciones, donde podría imponerse la propia voluntad aún frente a la resistencia. La posibilidad de oponerse al 
Blacha, L.E. (2014). El orden social en perspectiva sociológica. Collectivus, Revista de Ciencias Sociales, 1, (1), 4-27. Julio - Diciembre. ISSN: 2382-4018

poder, lo transforma en "la capacidad de un grupo de superar o neutralizar la resistencia de otros grupos a la realización de los propios intereses (de nuevo: materiales o ideales)" (Poggi, 2005, pp. 47-48). El poder es entonces la "posibilidad de hallar obediencia, entre ciertas personas, a un orden que posea determinado contenido" (VVAA, 1991, p. 37). Su efectividad aumenta con la mediación del aparato administrativo en las interacciones sociales, destacando la importancia del saber especializado, la organización, la técnica y la calculabilidad propias de las estructuras administrativas modernas.

La dominación es interpretada por Max Weber como el "poder autoritario de mando" (Bendix, 2000, p. 278), es un sentido restringido del poder que excluye la existencia de constelaciones de intereses en su interior. El control de una estructura administrativa de corte burocrático es necesario para la dominación, al permitir que se materialicen las decisiones de la clase gobernante. El aparato administrativo se convierte en medio y fin de y para la dominación que incide en el entramado de relaciones sociales y forma parte del fundamento del orden social.

El monopolio de la violencia legítima que define al Estado le permite delimitar sus funciones y fundamentar, a su vez, los monopolios de la dominación y de la administración centralizada de un territorio nacional. El cual conlleva -de forma permanente- un sistema tributario centralizado y una fuerza militar estable. En este sentido, el Estado es interpretado por Weber como un actor social que concentra un medio específico -la violencia que es considerada como socialmente legítima ${ }^{2}$ y promueve el desarrollo de acciones sociales. Esta institución puede imponer la ley a través de la "organización de una burocracia orientada racionalmente, que dependa de la autoridad central en el ejercicio de las funciones administrativas" (ob. Cit, p. 361). Su estructura administrativa se transforma en parte del fundamento del poder por la efectividad y el alcance que otorga a las decisiones políticas.

\footnotetext{
2 Esta perspectiva no excluye la existencia de hechos de violencia en una sociedad determinada pero sólo la coerción física que dictamina el Estado puede ser considerada como legítima. Otros tipos de violencia podrán ser perseguidos por el Estado en tanto no cuentan con legitimidad social. El carácter legítimo fundamentaría el uso de la violencia por parte del Estado que actúa como parte del sostén del orden social.
} 
Blacha, L.E. (2014). El orden social en perspectiva sociológica. Collectivus, Revista de Ciencias Sociales, 1, (1), 4-27. Julio - Diciembre. ISSN: 2382-4018

La burocracia moderna influye sobre interacciones, delimita y guía la socialización que fundamenta el orden social a través de la internalización de normas y pautas de comportamiento (Zabludovsky Kuper, 2007a). Es un marco de referencia para las interacciones sociales. Para Weber la burocratización es un proceso que puede definirse como "el medio específico para transformar" un "accionar de comunidad" en un "accionar social" ordenado racionalmente" (VVAA, 1991, p. 43). Su capacidad de mediar en las decisiones de los gobernantes y la realidad de los gobernados, es resultado del conocimiento experto que promueve y produce la misma estructura burocrática. El carácter relacional del poder weberiano ${ }^{3}$ permite interpretar a la burocracia como "moldeando" a los ciudadanos de un Estado mientras éstos delimitan -en menor grado- a la estructura administrativa y sus relaciones de poder.

La estructura administrativa se basa en reglas estipuladas que guían los asuntos oficiales, en donde cada funcionario debe prestar servicio según lo reglamentado y de acuerdo a criterios impersonales. Las aptitudes técnicas, demostradas a través de diplomas, son necesarias para la selección y clasificación de los funcionarios que la integran. Las prácticas administrativas del Estado moderno promueven un ethos característico en los funcionarios que se fundamenta en la selección originada en títulos académicos y capacitaciones específicas (Du Gay, 2012). El carácter práctico del poder circula en estos ámbitos administrativos estatales y amplía la importancia de esta institución en el entramado de relaciones sociales. En donde el propio Estado interactúa con múltiples grupos que compiten por legitimar su autoridad (Migdal, 2011, P. 34).

La importancia de la socialización como fundamento de las relaciones de poder toma en cuenta el carácter práctico de estas interacciones. Max Weber identifica en las prácticas políticas de las sociedades de masas una tensión característica entre la democracia y la organización racional burocrática. El sociólogo alemán propone el control político de la estructura administrativa, transformando a la actividad política en "mediador entre las cuestiones propias

\footnotetext{
${ }^{3}$ En tanto el autor alemán interpreta al poder como una acción social cuyo sentido está orientado a las acciones de otros.
} 
Blacha, L.E. (2014). El orden social en perspectiva sociológica. Collectivus, Revista de Ciencias Sociales, 1, (1), 4-27. Julio - Diciembre. ISSN: 2382-4018

del cálculo racional y la libertad individual" (Aronson, 2011, p. 118). El análisis del fundamento del orden social se torna más complejo cuando reconoce que "sin carisma o sin máquina burocrática que respalde, la política de cualquier partido moderno está abocada al fracaso" (Gonzalez García, 1992, p. 160) ${ }^{4}$. La sociología comprensiva debe tomar en consideración tanto aquellos aspectos racionales de la acción social, como aquellos caracterizados como irracionales. Para así poder dar cuenta del fundamento del orden social y su asimetría característica. La influencia de acciones "no racionales" se convierte en una preocupación central en el análisis weberiano que incorpora nuevas preocupaciones a la disciplina sociológica y que intenta superar el abordaje positivista de Auguste Comte. El poder adquiere un carácter práctico que actualiza la internalización de las normas sociales e influye consecuentemente en la socialización.

La sociabilidad desarrollada en el ámbito administrativo también conforma el fundamento de las relaciones de poder. Esta caracterización no es desarrollada en detalle por Max Weber pero será Wright Mills (1916-1962), quien subrayará su importancia para explicar el orden social imperante. Es una propuesta que forma parte de los estudios clásicos de las élites, aquellos que interpretan a la organización de la minoría gobernante como fundamento de su posición de privilegio en la estructura social. Wright Mills incorpora a esta perspectiva un abordaje de corte sociológico en donde se tienen en cuenta "los problemas de la biografía, de la historia y de sus intersecciones dentro de la sociedad, ha terminado su jornada intelectual" (Wright Mills, 2005, p.26). Propone que esa organización se enmarca en la socialización interna del grupo, en especial porque el autor reconoce que los individuos:

Rara vez conscientes de la intrincada conexión entre el tipo de sus propias vidas y el curso de la historia del mundo, los hombres corrientes suelen ignorar lo que esa conexión significa para el tipo de

\footnotetext{
${ }^{4}$ Una tensión que estudiará con mayor detenimiento el sociólogo alemán Robert Mitchels en su análisis de la social-democracia alemana en donde formulará su "Ley de Hierro de la Oligarquía".
} 
Blacha, L.E. (2014). El orden social en perspectiva sociológica. Collectivus, Revista de Ciencias Sociales, 1, (1), 4-27. Julio - Diciembre. ISSN: 2382-4018

hombres en que se van convirtiendo y para la clase de actividad histórica en que pueden tener parte. (Wright Mills, 2005, p.23).

Desarrolla una caracterización dinámica del poder que se vincula con la interpretación weberiana clásica. Se amplía, así, el alcance analítico del poder y su fundamento.

Para el sociólogo norteamericano los ámbitos administrativos, las instituciones educativas y el tiempo de ocio consolidan y actualizan las interacciones de los individuos que conforman la minoría gobernante. Fundamentando y potenciando las asimetrías de las relaciones de poder. Por medio del estudio de la sociedad estadounidense del New Deal, analiza los distintos ámbitos de la socialización de la elite del poder (Wright Mills, 1987). El espacio cobra especial importancia al articular y delimitar las interacciones que repercuten en las relaciones de poder imperantes. En los ámbitos de interacción compartidos la minoría gobernante actualiza sus lazos, mientras es posible la incorporación de nuevos miembros en el grupo gobernante, sin implicar cuestionamientos al orden social vigente. Se amplía la influencia analítica del entorno social como fundamento del orden social que acuña Weber.

La socialización compartida permite a la elite del poder tomar decisiones y actuar de forma coordinada a través del accionar interdependiente de sus miembros, quienes intercambian posiciones institucionales. Esta articulación resulta de los intereses compartidos de estos individuos, que se consolidan como resultado de la socialización. Los aspectos sociales del poder adquieren un carácter dinámico, que establece continuidades entre pasado y presente, adquiriendo potencialidades futuras. Un abordaje que podría ser interpretado como un cierto respaldo a la "teoría del conflicto" de Lewis Coser que intenta oponerse a la "teoría del orden" funcionalista de Talcott Parsons (Alexander, 2000, p. 109).

La intercambiabilidad de funciones de los miembros de este grupo, es un rasgo central para la caracterización que formula Wright Mills y que van más allá de una clase ociosa como plantea Thorstein Veblen. Las posiciones 
Blacha, L.E. (2014). El orden social en perspectiva sociológica. Collectivus, Revista de Ciencias Sociales, 1, (1), 4-27. Julio - Diciembre. ISSN: 2382-4018

gobernantes adquieren múltiples fundamentos que complejizan la explicación del orden social y amplían el alcance de las estructuras administrativas. carácter interdependiente de estos individuos puede ser interpretado por los gobernados como propiedades carismáticas. Esta caracterización puede ser entendida como otro punto de contacto entre la teoría weberiana y la sociología de Wright Mills.

En el esquema propuesto por Wright Mills hay tres órdenes principales en las sociedades modernas: el político, donde se encuentran:

Las instituciones mediante las cuales los hombres adquieren, manejan e influyen en la distribución de poder y autoridad dentro de las estructuras sociales"; el económico, con las entidades "mediante las cuales los hombres organizan la mano de obra, los recursos y los medios técnicos en orden a la producción y distribución de los bienes y servicios"; y el militar, con sus instituciones "mediante las cuales los hombres organizan la violencia legítima y supervisan su uso. (Agulla, 1987, p. 471).

Su vinculación genera una compleja caracterización del orden social en relación a la propuesta weberiana. Se amplía el alcance e importancia de la socialización como fundamento de las relaciones asimétricas de poder, mientras se destaca la importancia de las estructuras administrativas. A través de las instituciones gubernamentales, las interacciones de la minoría gobernante adquieren alcance nacional y consolidan sus abarcativas decisiones. Por este motivo el autor destaca la importancia de los estratos cimeros, pues inculcan en los individuos de la masa social ${ }^{5}$ proyectos que no son los suyos pero que sin embargo los viven como propios.

En esta perspectiva, el fundamento del orden social se vincula con las funciones que lleva a cabo la elite del poder. Esta caracterización de la clase

\footnotetext{
5 La distinción de la teoría elitista entre una minoría gobernante y una masa gobernada, hace referencia a que en el grupo mayoritario existen un cúmulo de individuos aislados que se encuentran aprisionados por sus preocupaciones personales que les impiden desarrollar objetivos y proyectos políticos comunes. Una preocupación que, a comienzos del siglo XX, adquiere gran importancia para la sociología y la teoría política. Sus implicancias se reflejan en los proyectos antidemocráticos de la primera mitad del siglo XX.
} 
Blacha, L.E. (2014). El orden social en perspectiva sociológica. Collectivus, Revista de Ciencias Sociales, 1, (1), 4-27. Julio - Diciembre. ISSN: 2382-4018

gobernante presta especial atención a los aspectos sociales del poder, a la vez que toma en consideración la importancia de las estructuras administrativas en las sociedades de masas modernas. A diferencia de los autores elitistas clásicos como Gaetano Mosca, Vilfredo Pareto y Robert Michels. La elite del poder no es una "clase dirigente", pues esta última otorga excesiva autonomía al orden político. Al mismo tiempo que no lo interrelaciona con los órdenes económico y militar que Wright Mills considera de gran importancia en las sociedades modernas. Tampoco es una aristocracia, porque no es un grupo dirigente basado en la nobleza hereditaria. Los orígenes comunes de sus miembros se explican por la socialización compartida, en particular a través de la educación, que resulta en la capacitación y selección de los individuos que conforman los elencos de gobierno.

En la elite del poder se combinan la socialización con la dirección de las estructuras administrativas, resultando en un grupo que decide los acontecimientos nacionales en un país como los Estados Unidos. Cabe destacar el estudio de caso desarrollado por Wright Mills, en oposición a la propuesta de otros teóricos elitistas clásicos o el propio Weber, con sus caracterizaciones analíticas amplias. La intercambiabilidad de funciones de este elenco gobernante, refleja la complejidad y el crecimiento de las estructuras administrativas en relación a lo teorizado por Max Weber. La interdependencia institucional tiene su correlato en la intercambiabilidad de funciones de los gobernantes y caracteriza al orden social con un fundamento complejo, donde las relaciones de poder son asimétricas. A través de la socialización de la elite se explican las diferentes cuotas de poder que poseen los distintos grupos en el entramado de relaciones sociales que constituye la sociedad.

La asimetría en las relaciones de poder también se vincula con la efectividad que tiene la intercambiabilidad de funciones al interior de la elite del poder. Wright Mills destaca el carácter práctico de las interacciones de poder que resulta en la interdependencia de los individuos y de los distintos grupos sociales. Estas vinculaciones son posibles por la socialización compartida que 
Blacha, L.E. (2014). El orden social en perspectiva sociológica. Collectivus, Revista de Ciencias Sociales, 1, (1), 4-27. Julio - Diciembre. ISSN: 2382-4018

la fundamenta, donde la internalización de normas sociales se convierte en el fundamento del orden social y de la posición de privilegio de la elite del poder.

El vínculo entre socialización y orden social también incluye el uso y resignificación de los elementos culturales compartidos, a través de los cuales se incorporan las normas sociales. Es un proceso dinámico en el cual los actores y las instituciones se constituyen y consolidan de forma interdependiente. Este es el segundo abordaje propuesto: El de la sociología figuracional de Norbert Elias. En esta perspectiva el ámbito de interacción permite la "conformación del espacio, donde los respectivos hombres, si no juntos, al menos en unidades parciales, conviven o pueden convivir efectivamente" (Elias, Soc. Cortesana, p. 62).

\section{Individuos e instituciones como fundamento del orden social interdependiente}

La sociología figuracional (Weiler, 1998) de Norbert Elias (1897-1990) es una perspectiva de amplio alcance temporal y espacial que analiza el proceso capaz de vincular los cambios en el comportamiento individual con las transformaciones de la organización social. Las bases del orden social adquieren un carácter dual: son procesos sociales y, al mismo tiempo, individuales. Entre ambos hay una interdependencia que destaca su dinamismo. Es una perspectiva que va más allá del intento parsoniano de concebir "la estructura social de una manera que no amenace la subjetividad y la libertad" (Alexander, 2000, p. 31) Para Elias "las sociedades no son más que configuraciones de hombres interdependientes" (Elias, 1996, p. 31).

El abordaje figuracional estudia el "proceso civilizatorio" que incluye tanto el autocontrol individual, como la consolidación de los monopolios fiscales y de la violencia legítima por parte del Estado. El propio Elias destaca "Ios impulsos de la creciente centralización del poder" (Elias, 1996, p. 10) que implican estas transformaciones de carácter social e individual. A diferencia de la propuesta de Parsons no pone entre paréntesis los procesos históricos y los datos concretos de la realidad para una mayor implicancia teórica, sino que son parte fundamental de la perspectiva desarrollada por Elias. Se constituye un 
Blacha, L.E. (2014). El orden social en perspectiva sociológica. Collectivus, Revista de Ciencias Sociales, 1, (1), 4-27. Julio - Diciembre. ISSN: 2382-4018

"marco de referencia" que resulta ineludible para comprender la organización de las sociedades modernas y las interacciones que establecen sus miembros. El poder adquiere aquí un carácter dinámico, al ser interpretado como un proceso cuya trayectoria puede reconstruirse de forma analítica. Blacha (2013) destaca también que esta aproximación teórica siempre resulta en un margen de incertidumbre que imposibilita la plena delimitación de los resultados. Existe un carácter "incierto" como propio de "lo social", que la sociología consigue minimizar pero no eliminar.

El proceso de civilización implica un cambio de las relaciones humanas en una dirección determinada que nunca se detiene. Está regido "por leyes propias de la red de individuos humanos interdependientes" (Elias, 1990, pp. 58-59) que conforman la sociedad y que Elias define como figuración o configuración ${ }^{6}$. Supone la gradual internalización de las coacciones sociales externas, así como también que la satisfacción de las necesidades humanas se realiza, paulatinamente, "entre los bastidores de la vida social y se carga de sentimientos de vergüenza" (Elias, 1997, p. 449). Se incrementa el control individual de la naturaleza animal del hombre a través de la internalización de normas. La civilización conlleva mayor previsión y reflexión de las acciones sociales y de las intenciones de los actores, como resultado de la división del trabajo, la interdependencia y el monopolio de la violencia física legítima en manos del Estado. A pesar de ciertos puntos de contacto, la perspectiva figuracional plantea un abordaje distinto al desarrollado por Max Weber y Charles Wright Mills.

Para Elias las transformaciones en las relaciones humanas tienen una dirección determinada e identificable. Esta subraya el carácter interdependiente entre el entramado de relaciones sociales y los individuos que las llevan a cabo (Zabludovsky Kuper, 2007). La sociología figuracional da cuenta de este vínculo a través las dos herramientas analíticas fundamentales que interpretan

\footnotetext{
${ }^{6}$ La figuración o configuración (según las traducciones de las obras de Norbert Elias) es un concepto central en la sociología del autor alemán y hace referencia al entramado de relaciones intersubjetivas que realizan individuos interdependientes. El concepto adquiere un carácter dinámico al destacar al carácter procesal de las acciones sociales. Este contexto de interacción otorga carácter social a las acciones individuales al mismo tiempo que el resultado de éstas actualiza ese carácter interdependiente que vincula a los actores sociales.
} 
Blacha, L.E. (2014). El orden social en perspectiva sociológica. Collectivus, Revista de Ciencias Sociales, 1, (1), 4-27. Julio - Diciembre. ISSN: 2382-4018

e interpelan el proceso civilizatorio y sus consecuencias. La sociogénesis da cuenta de la escala social de las transformaciones, mientras que la psicogénesis refiere a una perspectiva individual. Ambos elementos metodológicos son interdependientes y permiten abordar estos cambios vinculados con la división social del trabajo. A la que refiere Emile Durkheim, el monopolio de la violencia física legítima por parte del Estado que postula Max Weber y la constitución del sujeto moderno sobre la que reflexionan diversos autores desde Sigmund Freud hasta Georg Simmel.

La ley fundamental sociogenética es que "la historia de una sociedad se refleja en la historia interna de cada individuo" (Heinich, 1999, p. 12). La psicogénesis es un fenómeno "perceptible a escala colectiva" (ob. Cit, p. 13), a partir de la cual Elias reconstruye la historia del proceso civilizatorio europeo. El incremento de la interdependencia entre actores y la delimitación de la violencia física promueven el surgimiento de un aparato social donde las coacciones que los hombres ejercen unos sobre otros "se transforman en autocoacciones" (Elias, 1997, p. 460). Este proceso implica una mayor previsión y una reflexión permanente por parte del individuo sobre sí mismo y también sobre su entorno de interacción.

La transformación de coacciones externas en autocoacciones implica la internalización de las normas sociales. Esta especificidad del abordaje figuracional es parte de una lectura sociológica de El malestar en la cultura de Sigmund Freud. Para el padre del psicoanálisis los elementos culturales disponibles delimitan las interacciones sociales en general y las relaciones de poder en particular. La psicogénesis amplía el abordaje freudiano cuando destaca con mayor énfasis la influencia de los aspectos sociales en la configuración de los individuos. Si Freud fundamenta el orden social a través de la culpa y las autocoacciones, Elias enfatiza la internalización de las normas sociales. También Talcott Parsons subraya la importancia de "la formación del superyó como explicación prototípica de la internalización de las normas" (Alexander, 2000, p. 39). Elias incorpora el superyó freudiano al devenir histórico, en donde lo social se convierte en un marco de certezas que transforma en sociales las acciones individuales. Las instituciones, como parte 
Blacha, L.E. (2014). El orden social en perspectiva sociológica. Collectivus, Revista de Ciencias Sociales, 1, (1), 4-27. Julio - Diciembre. ISSN: 2382-4018

del contexto de interacción, cobran una importancia explicativa destacada que diferencia a la sociología figuracional del psicoanálisis de Freud y se vincula con el método utilizado por Weber y Wright Mills.

En la sociología figuracional la estabilidad de las autocoacciones se encuentran en "íntima relación con la estabilidad creciente de los órganos sociales centrales" (Elias, 1997, pp. 453-454). Los procesos de psico y sociogénesis resultan interdependientes y por medio de ellos se destaca la importancia explicativa del contexto de interacción social. Elias propone un "desarrollo" paralelo entre la internalización de la norma social y la consolidación de las estructuras administrativas que resultan en el Estado burocrático y racional. Es un "marco de referencia" ineludible para comprender la organización de las sociedades modernas que depende de "la posibilidad de que experiencias que ha tenido una determinada generación se transmitan como saber social aprendido, a las siguientes generaciones" (Elias, 1996, p. 24).

La interdependencia entre las autocoacciones y las estructuras administrativas, supone una caracterización compleja del entorno de interacción social. El cual también influye en la interpretación del orden social, mientras potencia los aspectos sociales de las relaciones de poder. En la teoría de Elias, la "configuración" es un modelo cambiante en el cual los individuos, como si fueran jugadores, con sus acciones y entendimiento, actúan como parte de un tejido de tensiones interdependientes. La configuración influye en los individuos y sus acciones, ampliando la importancia de la socialización y la interdependencia que destaca Wright Mils como fundamento del orden social. Una idea de desarrollo en donde el orden es resultado del progreso, tal como sostiene el propio Auguste Comte (Forte, 1998, p. 18).

El carácter dinámico de la sociología figuracional se origina en su interpretación de lo social como un proceso que se encuentra en constante constitución y actualización. Elias propone fundamentar su teorización en una perspectiva social interdisciplinar que reconoce influencias de la sociología, la historia, el psicoanálisis, la antropología y la ciencia política. Su amplio alcance temporal permite acrecentar la influencia de la socialización en las relaciones 
Blacha, L.E. (2014). El orden social en perspectiva sociológica. Collectivus, Revista de Ciencias Sociales, 1, (1), 4-27. Julio - Diciembre. ISSN: 2382-4018

de poder. El autor hace referencia a que configuraciones que parecieran conservarse idénticas pueden estar "compuestas de individuos diversos que cambian más rápidamente" (Elias, 1996, p. 25). El orden social reconoce continuidades y rupturas entre pasado y presente, que se conjugan con expectativas futuras. La flexibilidad de la configuración da cuenta de esta situación con un abordaje complejo del fundamento del orden social que también adquiere los aspectos potenciales del poder. Un abordaje que se contrapone al equilibrio parsoniano que actúa "como una pauta abstracta para juzgar los requerimientos de la sociedad" (Alexander, 2000, p. 46) para mensurar la efectividad del orden social.

Esta perspectiva puede complementarse con la sociología de la cultura que desarrolla Pierre Bourdieu, que es también una sociología del poder. El carácter práctico de esta propuesta se vincula con la gubernamentalidad que Michel Foucault utiliza para interpelar al biopoder. Y que le permite destacar la influencia de las prácticas estatales en la conformación del sujeto moderno.

\section{La naturalización de las relaciones de poder y la gubernamentalidad}

En la sociología de Pierre Bourdieu (1930-2002), tal como sucede con Norbert Elias, el actor y el entramado social están mutuamente determinados. El concepto de habitus ${ }^{7}$ refleja la interdependencia individuo-sociedad. Es un término muy importante para esta perspectiva sociológica y debe ser entendido como "sistemas de disposiciones duraderas y transferibles, estructuras estructuradas predispuestas a funcionar como estructuras estructurantes" (Bourdieu, 2007, p. 86).

Si la legitimidad es el fundamento de la teoría weberiana del poder, la "naturalización" de las prácticas sociales que conforman los habitus es la

\footnotetext{
${ }^{7}$ El habitus debe ser entendido como una estructura estructurante que determina lo que un individuo puede o no hacer. De este modo permite al actor economizar el cálculo y la reflexión a través del uso de esquemas de clasificación y de percepción que se vinculan con el orden social vigente. También concede cierto grado de libertad de acción. A través de este concepto Bourdieu da cuenta del carácter actualizable de las relaciones de poder mediante las interacciones sociales. El orden social se complejiza al tener en cuenta aspectos materiales y simbólicos. Para el sociólogo francés, el capital cultural adquiere una importancia destacada como fundamento de un orden social determinado a través de las distintas esferas sociales, a las que define como "campos".
} 
Blacha, L.E. (2014). El orden social en perspectiva sociológica. Collectivus, Revista de Ciencias Sociales, 1, (1), 4-27. Julio - Diciembre. ISSN: 2382-4018

preocupación central de Bourdieu. El habitus relaciona las instituciones, la sociedad y el individuo como partes de "lo social". Su carácter actualizable y naturalizable se vincula con la potencialidad del poder que explica los alcances del fundamento del orden social. También permite reconocer los conocimientos prácticos que los individuos utilizan en cada una de sus acciones con implicancias sociales.

El sociólogo francés entiende que a través de un prolongado proceso de diferenciación, "el mundo social moderno se descompone en una multitud de microcosmos, los campos" (Chauviré y Fontaine, 2008, p. 14). Estos campos son ámbitos estructurados de posiciones "que pueden ser analizadas independientemente de las características de sus ocupantes (en parte determinadas por ellas)" (ob. Cit, p. 15). Cada campo tiene un tipo de capital específico que es en parte material, en parte simbólico y cuya posición determina la jerarquía dentro del ámbito de interacción de referencia. Bourdieu destaca que los campos no son estructuras fijas, sino que son resultado de los procesos que conforman la historia de ese ámbito.

La multiplicidad de campos existentes dan cuenta de la diferenciación que promueve el mundo social moderno y las múltiples dimensiones de su complejo orden social. Bourdieu promueve una caracterización polimórfica del capital que "permite construir un modo de representación más en condiciones de revelar la estructura, el sistema de relaciones y de dependencias, de todo universo social" (ob. Cit, p. 23). En este sentido puede interpretarse este abordaje como "una sociología de la dominación y de la denuncia de la dominación, inclusive y sobre todo allí donde a su juicio está más oculta" (Chauviré y Fontaine, 2008, p. 43).

Esta perspectiva concede gran importancia a la socialización como parte constitutiva de las relaciones de poder, tal como sucede con la elite del poder de Wright Mills. A diferencia del teórico norteamericano, esta sociología de la cultura otorga mayor autonomía al individuo. Atribuyéndole un importante manejo de los elementos culturales disponibles sobre los que teorizan Freud y Elias. La socialización adquiere un carácter práctico, como conjunto de herramientas que utilizan los actores para llevar a cabo sus interacciones. Por 
Blacha, L.E. (2014). El orden social en perspectiva sociológica. Collectivus, Revista de Ciencias Sociales, 1, (1), 4-27. Julio - Diciembre. ISSN: 2382-4018

medio de las prácticas se renueva la socialización individual, se amplía la interdependencia social de los individuos y se actualiza el fundamento del orden social.

La internalización de las normas sociales adquiere tal aceptación subjetiva que naturaliza prácticas y las convierte en parámetros que los individuos utilizan para percibir la realidad social e interpelar a los distintos actores e instituciones. Los habitus, como esquemas y pautas compartidas de pensamiento, son las herramientas utilizadas para transformar en sociales las acciones individuales y consolidar el orden social. En esta caracterización del poder tampoco se excluye la importancia de las instituciones administrativas como característica de las sociedades modernas. Así como espacios de socialización con una racionalidad distintiva, tal como propone Paul Du Gay para el caso de Max Weber.

Bourdieu identifica en la sociedad francesa una "nobleza de Estado", que se basa en: "meritocracia, escuela libertadora, servicio público" (Bonnewitz, 2006, p. 40). Los actores que conforman esta clase de expertos fueron centrales en la constitución del Estado moderno en oposición al Antiguo Régimen. Bourdieu, (2012) su rol "liberal" se combina con la defensa acérrima de su posición de privilegio dentro de la estructura estatal. El carácter actualizable que esta perspectiva reconoce en las interacciones sociales, también incluye a la estructura administrativa en un doble rol: como constituyente y como constitutiva de lo social. El rol central de estas instituciones destaca la importancia del capital cultural en las sociedades modernas como parte del fundamento del orden social. La internalización de normas sociales, como parte del capital cultural, amplía el alcance de las relaciones de poder y supone estrategias defensivas por parte de las clases gobernantes. Sin renunciar al carácter dinámico que Elias reconoce en las interacciones sociales, Bourdieu propone estudios de casos concretos en sus análisis de las estructuras administrativas francesas y de las estrategias educativas de estos funcionarios estatales.

A diferencia de los procesos de psico y sociogénesis de la sociología figuracional, los habitus condensan en un mismo término las prácticas que 
Blacha, L.E. (2014). El orden social en perspectiva sociológica. Collectivus, Revista de Ciencias Sociales, 1, (1), 4-27. Julio - Diciembre. ISSN: 2382-4018

articulan al actor y a la sociedad. Un concepto que puede ser interpretado como la base de "la reproducción del orden social" que adquiere una disposición duradera en el sujeto socializado. Este carácter continuo reorganiza las estructuras del habitus y posibilita el "cambio", al mismo tiempo que se reproducen las estructuras sociales vigentes (Tovillas, 2010). La mutabilidad del habitus permite establecer una continuidad entre pasado, presente y futuro, tal como sugiere Elias, aunque Bourdieu pareciera no intentar un rastreo exhaustivo de los condicionantes que configuraron un habitus de escala occidental.

El carácter actualizable del habitus se combina con la internalización de las normas sociales, con la transformación de coacciones en autocoacciones y con el establecimiento de estructuras administrativas que seleccionan individuos para reproducir la asimetría de las relaciones sociales. En la perspectiva desarrollada por Bourdieu los aspectos culturales forman parte de las relaciones de poder y conforman, también, el fundamento del orden social. Se destaca su carácter dinámico que es a la vez actualizable y flexible.

La flexibilidad de los habitus, que también es parte del fundamento del orden social, potencia los alcances de la socialización que conforman las relaciones de poder que estudia Wright Mills. Las estrategias familiares y los habitus de la elite del poder adquieren características más amplias e inclusivas en la perspectiva desarrollada por Bourdieu, al interpelar también a los funcionarios intermedios y su interacción con las capas superiores del aparato burocrático.

Para Bourdieu la estructura administrativa es un espacio de socialización donde se desarrollan y potencian las interacciones sociales. El sociólogo francés da cuenta de aquellos elementos culturales que internalizan los individuos para formar parte de la elite del poder. Los mismos que posibilitan la intercambiabilidad de funciones que Wright Mills identifica con el fundamento de la posición privilegiada de la minoría gobernante. La socialización moldea los habitus como parte de las estrategias implementadas por el grupo de referencia sin implicar la necesidad de un "director". La lógica subyacente de estos habitus se equipara a la concepción del proceso civilizatorio que 
Blacha, L.E. (2014). El orden social en perspectiva sociológica. Collectivus, Revista de Ciencias Sociales, 1, (1), 4-27. Julio - Diciembre. ISSN: 2382-4018

desarrolla Norbert Elias. Bourdieu propone ampliar la complejidad del orden social, al incorporar a su fundamento aristas sociales, culturales, económicas y políticas que atraviesan a toda la sociedad.

En la constitución del sujeto moderno cobran una importancia destacada las prácticas políticas implementadas desde las estructuras administrativas centrales del Estado. Es parte de la perspectiva desarrollada por Foucalt, quien identifica una lógica característica del accionar estatal que resulta en un biopoder disciplinar. Este extenso y complejo abordaje propone que no puede interpretarse la internalización de las normas sociales sin tener en cuenta la regulación disciplinar de las conductas y de las necesidades individuales.

Entre estas últimas, el autor francés incluye las características biológicas que, con la consolidación del Estado, adquieren implicancias políticas. Foucault propone un estudio multidisciplinar de amplio alcance que combina historia, sociología, ciencia política y sociología. Con el fin de identificar la consolidación de una "economía" característica de las estructuras administrativas centralizadas del Estado que resultan en la constitución del sujeto moderno y en el modo en que se vincula con sus pares. Una perspectiva analítica cuya complejidad y alcances deben ser sintetizados a ciertos resultados dentro de los límites que suponen este artículo académico.

En este sentido cabe destacar la importancia de la gubernamentalidad que debe ser entendida como la constitución de ciudadanos a través de políticas estatales. Las relaciones de poder se encarnan tanto en los gobernados como en los gobernantes, estableciendo una relación social de poder de carácter asimétrico. El poder se convierte en biopoder y es el aspecto que este trabajo intenta destacar dentro del abordaje desarrollado por Foucault. Los ámbitos de socialización y la diagramación de las estructuras edilicias donde éstas se llevan a cabo, reflejan el carácter social del poder y conforman, parte, del orden social imperante.

Foucault (1926-1984) propone una perspectiva donde el Estado utiliza métodos directos e indirectos para dar cuenta y acelerar la complejización del 
Blacha, L.E. (2014). El orden social en perspectiva sociológica. Collectivus, Revista de Ciencias Sociales, 1, (1), 4-27. Julio - Diciembre. ISSN: 2382-4018

entramado social. ${ }^{8}$ La politización de los rasgos biológicos del hombre es interpretada a través del biopoder que el filósofo francés identifica como una condición indispensable para el surgimiento del sistema capitalista en tanto permite el control de los cuerpos individuales en el sistema productivo. El fundamento del orden social adquiere rasgos biológicos, que podrían llevar a "encarnar" la internalización de las normas sociales.

El biopoder foucaultiano también se relaciona con la delimitación de espacios territoriales a través de la consolidación de los Estados-Nación. Las prácticas que estas instituciones desarrollan resultan en la configuración de una "población" entendida como un amplio conjunto de individuos que es identificable y mensurable a través de un espacio y tiempo delimitados. La satisfacción de las necesidades de este grupo es el fin último de las estructuras estatales a través de prácticas disciplinares que todo lo miden y clasifican. El carácter omnipotente que Foucault atribuye al biopoder estatal se fundamenta en mediciones regulares y controles constantes de las acciones individuales. Estas prácticas adquieren mayor efectividad cuando se invisibilizan e internalizan los controles.

El carácter dinámico de los procesos analizados por Foucault encuentra vínculos con aquellos interpretados por Elias. Ambos destacan la importancia de la calculabilidad en las sociedades modernas y su vinculación con la internalización de las normas sociales. La ampliación de los medios técnicos estatales incrementa el alcance territorial y temporal de las decisiones políticas, mientras que "los microprocesos biográficos deben vincularse con los macroprocesos históricos" (Foucault, 1999, 170). El fundamento del poder es individual y social, no sólo por la internalización de las normas sociales, sino porque los individuos encarnan un orden social determinado.

La corporización del poder que supone el biopoder destaca, tal como

\footnotetext{
8 La diversificación del entramado social también puede ser identificada como una preocupación fundacional de la sociología. Está detrás del concepto de alienación de Marx, del catecismo político de los industriales de Saint-Simon, así como de la división social del trabajo de Durkheim. En perspectivas sociológicas contemporáneas, se incluye también al capital cultural que fundamenta la distinción sobre la que teoriza Pierre Bourdieu. Excede al propósito de este trabajo incorporar el vínculo entre la complejización de la estructura social y la consolidación del orden social imperante.
} 
Blacha, L.E. (2014). El orden social en perspectiva sociológica. Collectivus, Revista de Ciencias Sociales, 1, (1), 4-27. Julio - Diciembre. ISSN: 2382-4018

propone Bourdieu, una naturalización de las normas sociales que enmascara su omnipresencia. Por este motivo se fundamenta la elección de parte de la obra de Foucault para este apartado. Para Foucault la resistencia es la parte del poder que resulta en un incremento de su potencialidad y destaca su carácter flexible. Una tecnología que individualiza al sujeto al insertarlo dentro de la especie humana, es una "individualización de las multiplicidades" (Foucault, 2007, p. 28) La resistencia como parte del fundamento de la asimetría del poder no supone un debilitamiento del orden social imperante sino su complejización, que refleja la efectividad de la naturalización de las normas sociales en las interacciones de poder.

\section{Reflexiones finales}

Las perspectivas sociológicas analizadas coinciden en subrayar el carácter social del poder, como expresión y fundamento del orden. La preocupación positivista por la reorganización total de la sociedad, es una constante en la sociología a través de la explicación del fundamento y realización del orden social. (Forte, 1998). La perspectiva clásica de la sociología comprensiva de Max Weber plantea que el poder es una relación social que necesita de una estructura administrativa para ampliar su alcance. El Estado es interpretado como un medio y también como un fin de las relaciones de poder imperantes que se desarrolla a través del proceso de burocratización que interpela a todas las acciones sociales. Surge un ethos característico de las estructuras burocráticas que internaliza normas y responsabilidades en los funcionarios, mientras amplía la incidencia del Estado en la sociedad.

El poder supone una relación entre individuos interdependientes donde la socialización fundamenta el orden social. Las interacciones sociales compartidas, suponen prácticas y un accionar coordinado por parte del grupo gobernante que permite establecer un vínculo asimétrico con los sectores gobernados. La élite del poder que caracteriza Wright Mills fundamenta su interdependencia en sus orígenes sociales comunes, sus carreras educativas similares y su tiempo de ocio compartido. Sus múltiples ocupaciones reflejan la complejización de la estructura administrativa y su imbricación en la vida social 
Blacha, L.E. (2014). El orden social en perspectiva sociológica. Collectivus, Revista de Ciencias Sociales, 1, (1), 4-27. Julio - Diciembre. ISSN: 2382-4018

moderna. En donde el Estado también compite con múltiples grupos tal como subraya Joel Migdal. El orden adquiere diversas aristas y está conformado por múltiples espacios de socialización que promueven prácticas de gubernamentalidad y ethos característicos de las estructuras administrativas.

La internalización de las normas sociales que implica la socialización, también puede caracterizarse como un proceso donde las coacciones se transforman en autocoacciones; mientras se consolidan las estructuras administrativas del Estado-Nación. El contexto de interacción adquiere una importancia analítica destacada en tanto permite explicar y, en cierto punto, predecir, prácticas que destacan la interdependencia de las transformaciones subjetivas y sociales. Este es el abordaje que la sociología figuracional lleva a cabo a través de la psico y la sociogénesis. La consolidación de un marco de certezas compartidas posibilita que las acciones individuales adquieran implicancias sociales. El orden social se inserta en un ámbito temporal y espacial determinado, convirtiéndose en un proceso dinámico, que establece continuidades y rupturas entre pasado y presente, promoviendo expectativas futuras.

Las autocoacciones, como construcción social y dinámica, adquieren un carácter práctico en la sociología cultural y política de Pierre Bourdieu. Los habitus permiten interpelar la internalización de las normas sociales a través de la efectividad de su naturalización. Una perspectiva que Michel Foucault identifica en el plano institucional con la gubernamentalidad que fundamenta la politización de los rasgos biológico del hombre, transformando al poder en un biopoder.

El conocimiento práctico que poseen los actores que destaca Bourdieu, también hace posible establecer resistencias al poder en el abordaje de Foucault. El fundamento del orden social debe reproducirse y actualizarse, como resultado de sus características sociales. La efectividad del poder no está dada sólo por las estructuras administrativas, sino por las estrategias de reproducción social que las propias prácticas ponen en juego.

El fundamento del orden social aumenta su alcance cuando no es percibido como algo externo a los individuos. Cuando la norma social es una 
Blacha, L.E. (2014). El orden social en perspectiva sociológica. Collectivus, Revista de Ciencias Sociales, 1, (1), 4-27. Julio - Diciembre. ISSN: 2382-4018

autocoacción naturalizada que permite que el incremento de la diferenciación individual resulte en mayor interdependencia social. La preocupación analítica por el orden social establece un punto de contacto entre las perspectivas sociológicas clásicas y las contemporáneas. En síntesis, inserta a la disciplina en el ámbito amplio de las ciencias sociales y destaca el carácter complejo, dinámico y flexible de su objeto de estudio.

\section{Bibliografía}

Alexander, J. (2000). Las teorías sociológicas desde la Segunda Guerra Mundial. Barcelona: Gedida editorial.

Agulla, J. C. (1987). Teoría sociológica. Sistematización histórica. Buenos Aires: Depalma.

Aron, R. (1996). Las etapas del pensamiento sociológico (*). MontesquieuComte-Marx-Tocqueville. Buenos Aires: Ediciones Fausto.

Aronson, P. P. (2011). La centralidad del carisma en la sociología política de Max Weber. Revista entramados y perspectivas de la carrera de sociología. Buenos Aires: Carrera de Sociología de la Facultad de Ciencias Sociales, Año 1, Vol. 1, junio 2011.

Bendix, R. (2000). Max Weber. Buenos Aires: Amorrortu Editores.

Blacha, L.E. (2013). Certezas e incertidumbres de lo social. Las perspectivas culturalista y figuracional. Revista de Ciencias Sociales. Segunda Época. Bernal: Universidad Nacional de Quilmes, Año 5, Número 23, otoño 2013.

Bonnewitz, P. (2006). La sociología de Pierre Bourdieu. Buenos Aires: Nueva Visión.

Bourdieu, P. (2007). El sentido práctico. Buenos Aires: Siglo XXI Argentina.

Bourdieu, P. (2012). La distinción. Criterio y bases del gusto. Buenos Aires: Taurus. 
Blacha, L.E. (2014). El orden social en perspectiva sociológica. Collectivus, Revista de Ciencias Sociales, 1, (1), 4-27. Julio - Diciembre. ISSN: 2382-4018

Bourdieu, P. (2013). La nobleza de estado. Educación de elite y espíritu de cuerpo. Buenos Aires: Siglo Veintiuno Editores.

Chauviré, C. y Fontaine, O. (2008). El vocabulario de Bourdieu. Buenos Aires: Atuel.

Comte, A. (1988). Discurso sobre el espíritu positivo. Madrid: Alianza Editorial.

Du Gay, P. (2012). En elogio de la burocracia. Weber, Organización, Ética. Madrid: Siglo XXI España.

Elias, N. (1990). La sociedad de los individuos. Barcelona: Ediciones Península.

Elias, N. (1996). La Sociedad Cortesana. México: FCE.

Elias, N. (1997). El proceso de la civilización. Investigaciones sociogenéticas y psicogenéticas. Colombia: FCE.

Elias, N. (2002). Compromiso y distanciamiento. Barcelona: Ediciones Península.

Forte, M. A. (1998). Sociología, sociedad y política en Auguste Comte. Buenos Aires: EUDEBA.

Foucault, M. (1999). Historia de la sexualidad. 1- la voluntad de saber. México: Siglo XXI.

Foucault, M. (2007). Seguridad, territorio, publicación: Curso en el College de Frances: 1977-1978. Buenos Aires: Siglo XXI.

Foucault, M. (2012). Nacimiento de la biopolítica. Curso en el College de France (1978-1979). Buenos Aires: FCE.

Freud, S. (1999). El malestar en la cultura. Madrid: Editorial Biblioteca Nueva. 
Blacha, L.E. (2014). El orden social en perspectiva sociológica. Collectivus, Revista de Ciencias Sociales, 1, (1), 4-27. Julio - Diciembre. ISSN: 2382-4018

González García, J. M. (1992). Las huellas de Fausto La herencia de Goethe en la sociología de Max Weber. Madrid: Editorial Tecnos S.A.

Heinich, N. (1999). Norbert Elias. Historia y cultura en Occidente. Buenos Aires: Nueva Visión.

Le Rider, J., Plon, M.; Raulet, G. y Rey-Flaud, H. (2005). Sobre El malestar en la cultura de Sigmund Freud. Buenos Aires: Ediciones Nueva Visión.

Migdal, J. S. (2011). Estados débiles. Estado fuertes. México: FCE.

Poggi, G. (2005). Encuentro con Max Weber. Buenos Aires: Ediciones Nueva Visión.

Scribano, A. (2009). Estudios sobre Teoría Social Contemporánea: Bhaskar, Bourdieu, Giddens, Hambermas y Melucci. Buenos Aires: Ediciones Ciccus.

Tovillas, P. (2010). Bourdieu. Una introducción. Buenos Aires: Quadrata.

VVAA (1991). Sociología del poder. Buenos Aires: Centro Editor de América Latina.

Wacquant, L. (coordinador) (2005). El misterio del ministerio. Pierre Bourdieu y la política democrática. Barcelona: Editorial Gedisa.

Weiler, V. (comp) (1998). Figuraciones en proceso. Colombia: Utópica Ediciones.

Wright Mills, C. (1987). La elite del poder. México: FCE.

Wright Mills, C. (2005). La imaginación sociológica. México: FCE.

Zabludovsky Kuper, G. (2007). Norbert Elias y los problemas actuales de la sociología. México: FCE.

Zabludovsky Kuper, G. (coord.) (2007a). Sociología y cambio conceptual. México: Facultad de Ciencias Políticas y Sociales, UNAM. 